\title{
Optimization of Urea Based Protein Extraction from Formalin-Fixed Paraffin-Embedded Tissue for Shotgun Proteomics
}

\author{
Stephen A. Luebker and Scott A. Koepsell \\ Department of Pathology and Microbiology, University of Nebraska Medical Center, 985900 Nebraska Medical Center, \\ Omaha, NE 68198-5900, USA
}

Correspondence should be addressed to Stephen A. Luebker; stephen.luebker@unmc.edu

Received 20 June 2016; Accepted 9 August 2016

Academic Editor: Djuro Josic

Copyright (C) 2016 S. A. Luebker and S. A. Koepsell. This is an open access article distributed under the Creative Commons Attribution License, which permits unrestricted use, distribution, and reproduction in any medium, provided the original work is properly cited.

\begin{abstract}
Urea based protein extraction of formalin-fixed paraffin-embedded (FFPE) tissue provides the most efficient workflow for proteomics due to its compatibility with liquid chromatography electrospray ionization tandem mass spectrometry (LC-ESIMS/MS). This study optimizes the use of urea for proteomic analysis of clinical FFPE tissue. A series of protein extraction conditions manipulating temperature and buffer composition were compared to reduce carbamylation introduced by urea and increase protein detection. Each extraction was performed on a randomized pair of serial sections of homogenous FFPE tissue and analyzed with LC-ESI-MS/MS. Results were compared in terms of yield, missed cleavages, and peptide carbamylation. Lowering extraction temperature to $60^{\circ} \mathrm{C}$ decreased carbamylation at the cost of decreased protein detection and yield. Protein extraction for at least 20 minutes at $95^{\circ} \mathrm{C}$ followed by $60^{\circ} \mathrm{C}$ for 2 hours maximized total protein yield while maintaining protein detection and reducing carbamylation by $7.9 \%$. When accounting for carbamylation during analysis, this modified extraction temperature provides equivalent peptide and protein detection relative to the commercially available Qproteome ${ }^{\circledR}$ FFPE Tissue Kit. No changes to buffer composition containing $7 \mathrm{M}$ urea, $2 \mathrm{M}$ thiourea, and $1 \mathrm{M}$ ammonium bicarbonate resulted in improvements to control conditions. Optimized urea in-solution digestion provides an efficient workflow with maximized yields for proteomic analysis of clinically relevant FFPE tissue.
\end{abstract}

\section{Introduction}

We recently applied a urea in-solution digestion (UISD) method to prepare protein from FFPE tissue for liquid chromatography tandem mass spectrometry (LC-ESI-MS/MS), providing a more efficient workflow relative to Qproteome FFPE Tissue Kit [1]. UISD poses several advantages to other preparation techniques: preparation is carried out in a single tube minimizing sample handling, urea is LC-ESI-MS/MS compatible requiring no additional washing beyond desalting, and both of these factors enhance sample throughput. However, artificial carbamylation is introduced when using urea at elevated temperatures, reducing trypsin digestion efficiency. In solution, urea is in equilibrium with isocyanate and ammonium [2]. Between $\mathrm{pH} 7$ and 9, isocyanate reacts with $\alpha$-amines on $\mathrm{N}$-termini and $\varepsilon$-amines on lysine side chains of peptides to form carbamyl groups [3]. Trypsin digestion efficiency was reduced by carbamylation, and UISD had more missed cleavages and a lower lysine to arginine $(\mathrm{K}: \mathrm{R})$ peptide terminal amino acid ratio relative to the commercially available Qproteome FFPE Tissue Kit (Qkit) [1]. Ammonium bicarbonate, included in the UISD extraction buffer, inhibits carbamylation when using urea as a protein denaturant, but its efficacy is greatly reduced above $37^{\circ} \mathrm{C}[4$, 5]. Despite having this drawback, UISD preparation detected similar numbers of peptides and proteins obtained using Qkit and some not detected by Qkit with a bias toward arginine terminal peptides. It has been demonstrated previously that FFPE tissue shows high equivalence with fresh tissue, but FFPE preservation introduces peptide modifications, particularly lysine methylation [6]. As FFPE tissue appears to be an unreliable substrate for investigating lysine modifications, 
the introduction of lysine carbamylation primarily affects proteomic study by reducing cleavage efficiency. In addition, the introduction of artificial carbamylation with isotopically labeled urea can provide an alternative quantitative tool to conventional methods [7]. The benefits of UISD as a preparation method outweigh the drawback of reduced cleavage efficiency, and in this study we optimize its application to FFPE tissue.

There are multiple approaches which may enhance protein solubility and enhance digestion efficiency for UISD. In this study, we test each condition separately and some in combination to find the optimum identifiable peptide solubility while maintaining the minimum level of introduced carbamylation. Different factors including buffer composition, $\mathrm{pH}$, temperature of extraction, and duration of extraction were investigated.

\section{Materials and Methods}

An anonymized FFPE melanoma tumor tissue sample was obtained with Institutional Review Board approval. The tumor was fixed using 10\% neutral buffered formalin and processed by an automated processor into a paraffin-embedded block. Serial $4 \mu \mathrm{m}$ slices were made on a microtome and mounted on glass slides. The first and last slices were stained with hematoxylin and eosin to ensure the tissue was homogenous tumor cells across serial sections and to select tissue for analysis. Slide mounted FFPE tissue sections were deparaffinized twice in xylene for $5 \mathrm{~min}$ followed by two washes in $100 \%(\mathrm{v} / \mathrm{v})$ ethanol for $5 \mathrm{~min}$. The tissue was then hydrated in $85 \%(\mathrm{v} / \mathrm{v})$ ethanol for $1 \mathrm{~min}, 70 \%(\mathrm{v} / \mathrm{v})$ ethanol for $1 \mathrm{~min}$, and distilled water for $1 \mathrm{~min}$. Protein was macrodissected with a 30-gauge needle from pairs of serial sections that were randomized between each set of extraction conditions with a total area of $1650 \mathrm{~mm}^{2}$. Tissue was placed directly into a $2 \mathrm{~mL}$ microtube containing $160 \mu \mathrm{L}$ of freshly prepared $7 \mathrm{M}$ urea, $2 \mathrm{M}$ thiourea, and $1 \mathrm{M}$ ammonium bicarbonate with modifications outlined in Table 1 [1]. Protein digestion was carried out using reconstituted proteomics grade trypsin with concentrations outlined in Table 1 (Sigma-Aldrich, St. Louis, MO, USA). After digestion, 99.8\% acetic acid (Acros Organics, Fair Lawn, NJ, USA) was added dropwise to reduce to $\mathrm{pH}$ 4, and the solution was desalted using C18 Peptide Cleanup Tubes according to the manufacturer's instructions (Agilent Technologies Inc., Wilmington, DE, USA). Total protein was quantified by the reducing agent compatible bicinchoninic acid protein assay according to the manufacturer's instruction (Pierce, Rockford, IL, USA).

Three technical replicate injections from each extraction condition were analyzed using LC-ESI-MS/MS system in a nanospray configuration (ABSciex 6600 TripleTOF $^{\circledR}, \mathrm{AB}$ SCIEX, Framingham, MA, USA) coupled with Eksigent NanoLC 415 with a cHiPLC system (Eksigent, Dublin, CA, USA) as previously described [1]. The Paragon ${ }^{\mathrm{TM}}$ and Pro Group $^{\mathrm{TM}}$ algorithms were used for protein identification and grouping in ProteinPilot 5.0 (AB SCIEX, Framingham, MA, USA). Data analysis parameters included data-dependent analysis, $H$. sapiens as the species, iodoacetamide cysteine alkylation, and trypsin digestion, and the analysis was carried out both with and without urea denaturation considered as a special factor. All data files were searched using a UniProtKB/SwissProt database downloaded in August of 2015. Positive protein detection for comparisons between methods was defined as two peptide matches per protein and a global false discovery rate of $1 \%$. Positive peptide detection was limited to a global false discovery rate of $1 \%$.

\section{Results and Discussion}

A series of conditions were tested to inhibit peptide carbamylation and to maximize protein yield (Table 1). Peptide carbamylation was an important factor for the performance of UISD that can affect spectral data analysis. A summary of results from ProteinPilot without urea denaturation considered as a special factor for data analysis is shown in Table 2 and the summary of results from ProteinPilot with urea denaturation considered as a special factor is shown in Table 3. The improvements with this search setting are demonstrated by the gain in spectra and peptides detected at $<1 \%$ FDR. Improvements in the identification of peptide spectra indicate better detection of peptides with urea denaturation induced artifacts. All UISD conditions increased the number of spectra, peptides, and proteins detected with urea denaturation considered as a special factor (Tables 2 and 3). Additionally, the number of carbamyl groups detected and the number of missed cleavages detected both increased for all UISD conditions under the same search parameters (Tables 2 and 3). The most significant improvement for UISD is that protein and peptide detection were better than Qkit for multiple conditions tested when accounting for urea induced modifications, and the values in Table 3 are used in further comparisons between methods.

The Paragon algorithm is used in ProteinPilot to identify peptides from mass spectra measured during LC-ESIMS/MS. Shilov et al. give a complete description on how the Paragon algorithm uses a scoring method to modulate search space based on evidence from sequence tags [8]. Briefly, probabilities are calculated for peptide hypotheses based on predefined parameters set by the user such as digestion enzyme, alkylating agent, and special factors; these probabilities are empirically determined by measuring how frequently they occur [8]. This is an important feature of the algorithm for this study because the special factor of urea denaturation selected in the search settings provided better peptide detection for UISD preparation of FFPE tissue. Selecting urea denaturation accounts for the empirically determined frequency that urea induced modifications like carbamylation occur which are built into the algorithm to influence the probability of a given peptide hypothesis. In conjunction with peptide hypothesis probabilities, segment probabilities based on de novo sequence tags termed "Sequence Temperature Value" for regions of the sequence database and protein probabilities based on initial precursor mass filtered search are used to generate an overall probability that determines the search space segments of the sequence database [8]. 
TABLE 1: Summary of protein extraction conditions. Yield was calculated as the total $\mu \mathrm{g}$ of protein divided by the area of the tissue section multiplied by the section thickness of $4 \mu \mathrm{m}$.

\begin{tabular}{|c|c|c|c|c|c|c|c|c|}
\hline & Control & (A) & (B) & (C) & (D) & $(\mathrm{E})$ & $(\mathrm{F})$ & Qkit \\
\hline Extraction buffer & $\begin{array}{c}7 \mathrm{M} \text { urea } \\
2 \mathrm{M} \text { thiourea } \\
1 \mathrm{M} \mathrm{AmBic}\end{array}$ & & as $\mathrm{col}$ & & $\begin{array}{c}7 \mathrm{M} \text { urea } \\
2 \mathrm{M} \text { thiourea } \\
2 \mathrm{M} \mathrm{AmBic} \\
\text { pH } 7.2\end{array}$ & $\begin{array}{c}7 \mathrm{M} \text { urea } \\
2 \mathrm{M} \text { thiourea } \\
1 \mathrm{M} \mathrm{AmBic} \\
0.2 \% \\
\text { Zwittergent 3-16 }\end{array}$ & $\begin{array}{l}\text { Same as } \\
\text { control }\end{array}$ & $\begin{array}{l}\text { EXB plus } \\
\text { extraction buffer }\end{array}$ \\
\hline First temperature & $\begin{array}{l}95^{\circ} \mathrm{C} \\
1.5 \mathrm{hr}\end{array}$ & N/A & & & $\begin{array}{c}95^{\circ} \mathrm{C} \\
20 \mathrm{~min}\end{array}$ & & & $\begin{array}{l}100^{\circ} \mathrm{C} \\
20 \mathrm{~min}\end{array}$ \\
\hline Second temperature & N/A & & & $\begin{array}{l}80^{\circ} \mathrm{C} \\
2 \mathrm{hr}\end{array}$ & & $\begin{array}{l}60^{\circ} \mathrm{C} \\
2 \mathrm{hr}\end{array}$ & & $\begin{array}{l}80^{\circ} \mathrm{C} \\
2 \mathrm{hr} \\
\end{array}$ \\
\hline Trypsin digestion & \multicolumn{6}{|c|}{ Overnight $37^{\circ} \mathrm{C} 1: 20(\mathrm{w} / \mathrm{w})$} & $\begin{array}{c}30 \mathrm{~min} \\
50^{\circ} \mathrm{C} 1: 5 \\
(\mathrm{w} / \mathrm{w})\end{array}$ & $\begin{array}{c}\text { Overnight } 37^{\circ} \mathrm{C} \\
1: 20(\mathrm{w} / \mathrm{w})\end{array}$ \\
\hline Total protein $(\mu \mathrm{g})$ & 19.4 & 26.3 & 40.6 & 34.4 & 30.6 & $19.9^{*}$ & $16.4^{*}$ & 41.0 \\
\hline $\begin{array}{l}\text { Protein yield } \\
\left(\mu \mathrm{g} / \mathrm{mm}^{3}\right)\end{array}$ & 2.94 & 3.99 & 6.16 & 5.22 & 4.63 & 6.03 & 4.97 & 6.22 \\
\hline
\end{tabular}

${ }^{*}$ Protein extracted from a single section of tissue.

TABLE 2: Summary of LC-ESI-MS/MS data without considering urea denaturation as special factor in ProteinPilot. Detected peptides were limited to $1 \%$ global FDR. Detected proteins were limited to 2 peptides and $1 \%$ global FDR. Percent total carbamyl lysine was calculated as the number of total carbamyl groups out of the total number of peptides. Percent missed cleavages were calculated as the total number of missed cleavages out of the total number of peptides.

\begin{tabular}{|c|c|c|c|c|c|c|c|c|}
\hline & Control & Qkit & (A) & (B) & (C) & (D) & (E) & $(\mathrm{F})$ \\
\hline Detected spectra & 43657 & 67411 & 45073 & 49333 & 40871 & 45571 & 52207 & 35281 \\
\hline Detected proteins & 948 & 1141 & 891 & 1027 & 888 & 835 & 957 & 836 \\
\hline Detected peptides & 6318 & 9628 & 7104 & 7780 & 5868 & 7292 & 7153 & 6132 \\
\hline K-terminal peptides & 180 & 4394 & 2725 & 734 & 124 & 2552 & 411 & 301 \\
\hline R-terminal peptides & 6030 & 4986 & 4234 & 6936 & 5646 & 4627 & 6638 & 5718 \\
\hline Peptide K: R & 0.03 & 0.881 & 0.644 & 0.106 & 0.022 & 0.552 & 0.05 & 0.053 \\
\hline Carbamyl N-terminus & 506 & 12 & 36 & 564 & 451 & 241 & 468 & 420 \\
\hline Carbamyl lysine & 1211 & 2 & 33 & 1467 & 1066 & 428 & 1120 & 959 \\
\hline Total carbamyl groups & 1749 & 30 & 72 & 2057 & 1535 & 681 & 1612 & 1407 \\
\hline Percent total carbamylation & 27.7 & 0.3 & 1.0 & 26.4 & 26.2 & 9.3 & 22.5 & 22.9 \\
\hline Total missed cleavages & 3052 & 1004 & 2493 & 3728 & 2656 & 2517 & 3749 & 3833 \\
\hline Missed lysine cleavages & 2322 & 781 & 1811 & 3021 & 2077 & 1984 & 2796 & 2529 \\
\hline Missed arginine cleavages & 730 & 223 & 682 & 707 & 579 & 533 & 953 & 1304 \\
\hline Percent missed cleavages out of total peptides & 48.3 & 10.4 & 35.1 & 47.9 & 45.3 & 34.5 & 52.4 & 62.5 \\
\hline
\end{tabular}

Extraction temperature affects the total protein yield from FFPE tissue, but greater overall protein yield did not always result in the most detected proteins. The control condition with longest high temperature extraction yielded only $2.9 \mu \mathrm{g} / \mathrm{mm}^{3}$ but detected the most proteins of all UISD conditions (Table 3). Ikeda et al. and Fowler et al. found short term intense heating at $100^{\circ} \mathrm{C}$ for 20 minutes followed by extended mild heating at $60^{\circ} \mathrm{C}$ or $80^{\circ} \mathrm{C}$ for 2 hours provided the optimum protein recovery from FFPE tissue $[9,10]$. Similar conditions were applied to UISD starting with extraction at $60^{\circ} \mathrm{C}$ for 2 hours in condition (A) as shown in Table 1, and it yielded $1.1 \mu \mathrm{g} / \mathrm{mm}^{3}$ more than control. Even though condition (A) had greater overall protein yield, 347 fewer proteins were detected relative to control (Table 3). Extracting protein for 5 minutes at $95^{\circ} \mathrm{C}$ prior to 2 hours at $60^{\circ} \mathrm{C}$ provided no change to results relative to condition (A) (data not shown). Increasing extraction time at $95^{\circ} \mathrm{C}$ to 20 minutes prior to extraction at $60^{\circ} \mathrm{C}$ for 2 hours in condition (B) increased the total protein yield by $3.3 \mu \mathrm{g} / \mathrm{mm}^{3}$ relative to control. Longer extraction time at mild temperature used in condition (B) resulted in detection of only 16 fewer proteins than control while increasing the number of detected peptides by 1030 (Table 3 ). In condition (C), extraction at $95^{\circ} \mathrm{C}$ was maintained at 20 minutes, but it was followed by $80^{\circ} \mathrm{C}$ instead of $60^{\circ} \mathrm{C}$ for 2 hours (Table 1 ). Condition (C) yielded $2.3 \mu \mathrm{g} / \mathrm{mm}^{3}$ more protein than control but also resulted in detection of 44 fewer proteins.

Since the extraction temperature in condition (B) made the most improvement in peptide detection, the remaining conditions were tested using these extraction temperatures 
TABLE 3: Summary of LC-ESI-MS/MS data when considering urea denaturation as a special factor in ProteinPilot. Detected peptides were limited to $1 \%$ global FDR. Detected proteins were limited to 2 peptides and $1 \%$ global FDR. Percent total carbamyl lysine was calculated as the number of total carbamyl groups out of the total number of peptides. Percent missed cleavages were calculated as the total number of missed cleavages out of the total number of peptides.

\begin{tabular}{|c|c|c|c|c|c|c|c|c|}
\hline Extraction & Control & Qkit & (A) & (B) & (C) & (D) & (E) & $(\mathrm{F})$ \\
\hline Detected spectra & 63337 & 67411 & 46279 & 64889 & 59074 & 49213 & 68932 & 48689 \\
\hline Detected proteins & 1252 & 1141 & 905 & 1236 & 1208 & 852 & 1181 & 1060 \\
\hline Median percent sequence coverage & 11.4 & 15.2 & 15.5 & 11.9 & 10.6 & 16.0 & 10.9 & 10.7 \\
\hline $\begin{array}{l}\text { Percent sequence coverage interquartile } \\
\text { range }\end{array}$ & 15.9 & 21.1 & 21.0 & 17.5 & 14.8 & 23.7 & 16.3 & 15.7 \\
\hline Detected peptides & 9025 & 9628 & 7596 & 10055 & 8431 & 7731 & 9125 & 7862 \\
\hline Mean peptide length & $15 \pm 6$ & $13 \pm 5$ & $14 \pm 5$ & $15 \pm 6$ & $15 \pm 6$ & $14 \pm 5$ & $15 \pm 6$ & $16 \pm 6$ \\
\hline K-terminal peptides & 244 & 4394 & 2911 & 966 & 209 & 2739 & 513 & 369 \\
\hline R-terminal peptides & 8624 & 4986 & 4530 & 8936 & 8074 & 4875 & 8474 & 7343 \\
\hline Peptide K : R & 0.028 & 0.881 & 0.643 & 0.108 & 0.026 & 0.562 & 0.061 & 0.050 \\
\hline Carbamyl N-terminus & 283 & 12 & 76 & 200 & 200 & 136 & 180 & 194 \\
\hline Carbamyl lysine & 3722 & 2 & 89 & 3866 & 3466 & 1127 & 3427 & 3009 \\
\hline Total carbamyl groups & 5438 & 30 & 170 & 5268 & 4821 & 1368 & 4727 & 4196 \\
\hline Percent total carbamylation & 60.3 & 0.02 & 2.2 & 52.4 & 57.2 & 17.7 & 51.8 & 53.4 \\
\hline Total missed cleavages & 6795 & 1004 & 2747 & 6835 & 5950 & 2994 & 6485 & 6367 \\
\hline Missed lysine cleavages & 5705 & 781 & 2000 & 5908 & 5106 & 2438 & 5265 & 4717 \\
\hline Missed arginine cleavages & 1090 & 223 & 747 & 927 & 844 & 556 & 1220 & 1650 \\
\hline $\begin{array}{l}\text { Percent missed cleavages out of total } \\
\text { peptides }\end{array}$ & 75.3 & 8.1 & 36.1 & 68.0 & 70.6 & 38.7 & 71.1 & 81.0 \\
\hline
\end{tabular}

combined with changes to buffer composition (Table 1). In an attempt to reduce isocyanate formation, $3 \mathrm{M}$ ammonium bicarbonate (Sigma-Aldrich, St. Louis, MO, USA) alone was introduced to the extraction buffer, but carbamylation remained unchanged and fewer proteins were detected than control (data not shown). In condition (D), ammonium bicarbonate was increased to $2 \mathrm{M}$ and $\mathrm{pH}$ was reduced to 7.2 with $\mathrm{HCl}$ (Sigma-Aldrich, St. Louis, MO, USA) to test the effect of $\mathrm{pH}$ on extraction while maintaining a higher concentration of ammonium. Total protein yield for condition (D) was $1.6 \mu \mathrm{g} / \mathrm{mm}^{3}$ lower than condition (B), and it detected 384 fewer proteins and 2324 fewer peptides. One major drawback for using neutral $\mathrm{pH}$ to enhance digestion efficiency is that extraction buffers with $\mathrm{pH}>8$ have been shown previously to be important for protein yield [11].

Other buffer changes were made to maximize solubility and protein yield beyond gains seen with temperature manipulation. In order to approach protein yield of Qkit, $6 \% \beta$ mercaptoethanol (Sigma-Aldrich, St. Louis, MO, USA) was added for extraction under reducing conditions, but yield and protein detection were reduced relative to control (data not shown). Shen et al. found that $0.2 \%$ Zwittergent $3-16$ yielded better results than buffer containing $8 \mathrm{M}$ urea, and the result was attributed to the enhanced lytic strength of the detergent [12]. In order to enhance cell lysis and protein solubility, 0.2\% Zwittergent 3-16 (Santa Cruz Biotechnology, Dallas, TX, USA) was included in the extraction buffer for condition (E), and this was combined with the extraction temperatures from condition (B) (Table 1). The addition of $0.2 \%$ Zwittergent
3-16 decreased total protein yield $1.19 \mu \mathrm{g} / \mathrm{mm}^{3}$ relative to condition (B), and 930 fewer peptides and 55 fewer proteins were detected (Table 3). Due to the limited amount of available clinical tissue that was used for this study, only a single tissue section was available to test the effect of Zwittergent 3-16 on total protein yield. As the total yield for condition (E), $6.01 \mu \mathrm{g} / \mathrm{mm}^{3}$, was only slightly lower than the $6.16 \mu \mathrm{g} / \mathrm{mm}^{3}$ yield for condition (B) and protein and peptide detection levels were within previously seen ranges, a second replicate was not included for this modification. In addition, the number of proteins and peptides detected was not sufficiently different from condition (B) to justify a second tissue section.

After maximizing the peptide detection and total protein yield of UISD, the second goal for manipulating extraction temperature was to limit lysine carbamylation for enhanced digestion efficiency. The percentage of carbamylated peptides reached a minimum of $2.2 \%$ for UISD with only $60^{\circ} \mathrm{C}$ extraction in condition (A), and it also resulted in $\mathrm{K}: \mathrm{R}$ of 0.643 , the highest obtained using UISD. Condition (B) had 7.9\% less total carbamylation than control while detecting 1030 more peptides. The percentage of missed cleavages out of the total number of peptides was $7.3 \%$ lower and total carbamylation was $7.9 \%$ lower for condition (B) relative to control. Condition (C) reduced carbamylation by only $3.1 \%$ relative to control.

As an alternative to decrease lysine carbamylation, reduction of $\mathrm{pH}$ to near 7 should increase bias toward $\mathrm{N}$-terminal 


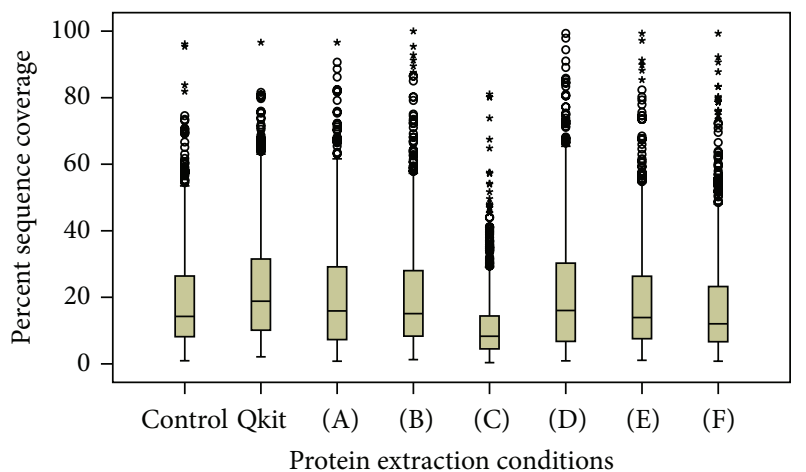

(a)

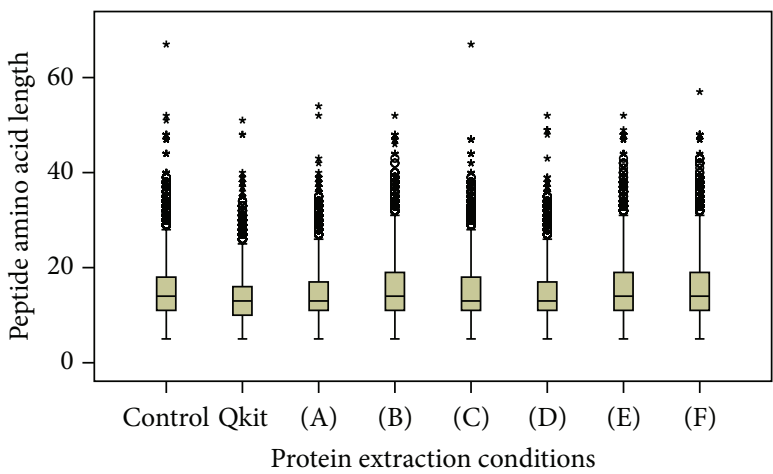

(b)

FIGURE 1: Side-by-side boxplots of detected protein percent sequence coverage (a) and peptide amino acid length (b) between each set of extraction conditions. Protein sequence coverage at the 95\% confidence level and peptide lengths were detected by analysis in ProteinPilot ${ }^{\mathrm{TM}}$ using urea denaturation as a special factor.

carbamylation rather than lysine carbamylation since $\alpha$ amines react faster at more neutral $\mathrm{pH}$ than $\varepsilon$-amines [3]. Condition (D) reduced $\mathrm{pH}$ to 7.2 with $2 \mathrm{M}$ ammonium bicarbonate and successfully decreased total carbamylation to $17.7 \%$ compared to $52.4 \%$ for condition (B) using the same extraction temperature. The fraction of carbamyl lysine residues out of total peptides was reduced by $23.8 \%$ relative to condition (B), and carbamyl $\mathrm{N}$-termini only decreased by $0.2 \%$. Missed cleavages for condition (D) were also decreased by $29.3 \%$ relative to condition (B). The reduction in carbamylation for condition (D) approached condition (A) by lowering $\mathrm{pH}$ instead of temperature, but peptide and protein detection was decreased for both relative to condition (B) or control (Table 3). Both condition (A) and condition (D) had reduced carbamylation and showed smaller gains in terms of the number of proteins, peptides, and spectra gained when accounting for urea denaturation in the search conditions or not, further demonstrating the importance of accounting for urea induced modifications (Tables 2 and 3 ).

Elimination of high temperature extraction and neutral buffer $\mathrm{pH}$ both reduced carbamylation only at the cost of reduced overall protein and peptide detection. The sample is also heated at $37^{\circ} \mathrm{C}$ for overnight digestion, which is a long period to introduce additional peptide carbamylation at a slower rate. As an alternative to extraction manipulation, trypsin digestion was limited to 30 minutes at $50^{\circ} \mathrm{C}$ for condition (F) using extraction time and temperature from condition (B) in order to reduce overall sample exposure time to heating while maintaining adequate yields (Table 1 ). Condition (F) detected 192 fewer proteins and 1163 fewer peptides than control. Carbamylation for condition (F) was increased by $1.0 \%$ relative to condition (B). Missed cleavages were elevated for condition (F) relative to all other UISD conditions, and arginine missed cleavages in particular were elevated for condition (F), indicating reduced overall digestion efficiency for rapid digestion independent of lysine carbamylation (Table 3). Any enhancement cleavage efficiency at lysine residues was negated by reduced overall digestion efficiency under rapid digestion. Accelerated digestion reduces sequence coverage and has been cautioned against for complex protein mixtures [13]. As previously mentioned for condition (E), only a limited number of tissue sections were available for this study. A single tissue section replicate was used for condition ( $\mathrm{F}$ ) due to the clearly apparent reduction in digestion efficiency from the increased number of missed arginine cleavages from a single tissue section. In this study, overall digestion efficiency was reduced, but accelerated preparation may outweigh the reduced efficiency given the need for rapid sample preparation.

UISD provides a protein extraction workflow from FFPE tissue with minimal sample handling steps, but it introduces significant artificial modifications to peptides in the form of carbamylation. Carbamylation reduces trypsin digestion at lysine residues leading to the generation of predominantly arginine terminal peptides. Despite this bias, distribution of sequence coverage across the set of conditions is very similar to those obtained using Qkit with positive skew across all conditions (Figure 1(a)). The higher temperatures used in control and condition (C) both show a smaller interquartile range in addition to reduced median sequence coverage relative to all other conditions (Table 3). Hildonen et al. demonstrated that incomplete trypsin digestion provides more complete proteome coverage in a simple protein mixture by minimizing small peptide generation and decreased ion intensity [14]. The distribution of detected peptide lengths across the different conditions varied little (Figure 1(b)). UISD condition (B) had a slightly higher average peptide length of $15 \pm 6$ amino acids compared to Qkit with $13 \pm 5$. No advantage in sequence coverage was seen relative to Qkit in terms of overall distribution of protein sequence coverage, but conditions with the optimum temperature (B), (D), (E), and (F) all show greater numbers of proteins with very high sequence coverage as outliers in the distribution (Figure 1(a)). The lack of any improvement may be due to limitations of the mass detection range by LC-ESI-MS/MS for longer peptides or limited sampling due to the relatively short 60-minute elution gradient used for LC-ESI-MS/MS (Figure 1(a)). Improvements to sequence coverage and overall detection of peptides can be made by peptide fractionation prior to LC-ESI-MS/MS. As we 
pointed out in our previous paper analyzing this method, overall protein detection and total protein yield vary across studies using different instrumentation, tissue type, and data analysis methods, making direct comparisons difficult across studies [1]. When artifacts introduced by UISD using control conditions are accounted for during analysis, the optimized UISD condition (B) detects more proteins and peptides than Qkit with comparable distribution of sequence coverage and equivalent yield.

\section{Conclusion}

Protein extraction at $95^{\circ} \mathrm{C}$ for 20 minutes followed by $60^{\circ} \mathrm{C}$ for 2 hours provided the best total protein yield and best peptide detection for the tissue analyzed. Modifications to extraction buffer or digestion conditions all reduced overall performance for UISD. Despite artificially introducing carbamylation, the optimized UISD conditions detected more peptides and proteins relative to Qkit with a comparable distribution of protein sequence coverage making it a useful method for proteomic studies. During data analysis of mass spectra, considering urea denaturation as a special factor is important for maximizing protein and peptide detection with the Paragon algorithm. This study has two main limitations: first using only a limited amount of clinically available tissue for extraction method comparisons and second the inability to modify or view specific calculations in the proprietary software used to analyze mass spectra. UISD provides efficient protein extraction that can be applied to clinically relevant FFPE tissue for proteomic analysis providing a useful tool for target development in immunohistochemical studies.

\section{Competing Interests}

The authors have declared no conflict of interests.

\section{Acknowledgments}

The authors would like to thank the University of Nebraska Medical Center Chancellor's Program of Excellence Physician-Scientist Training Program for funding this research. They would like to thank Melinda Wojtkiewicz and the University of Nebraska Medical Center Mass Spectrometry and Proteomics Core Facility for acquiring mass spectrometry data.

\section{References}

[1] S. A. Luebker, M. Wojtkiewicz, and S. A. Koepsell, "Two methods for proteomic analysis of formalin-fixed, paraffin embedded tissue result in differential protein identification, data quality, and cost," Proteomics, vol. 15, no. 21, pp. 3744-3753, 2015.

[2] J. Walker and F. J. Hambly, "Transformation of ammonium cyanate into urea," Journal of the Chemical Society, Transactions, vol. 67, pp. 746-767, 1895.

[3] G. R. Stark, "Reactions of cyanate with functional groups of proteins. 3. Reactions with amino and carboxyl groups," Biochemistry, vol. 4, no. 6, pp. 1030-1036, 1965.
[4] S. Sun, J.-Y. Zhou, W. Yang, and H. Zhang, "Inhibition of protein carbamylation in urea solution using ammonium-containing buffers," Analytical Biochemistry, vol. 446, no. 1, pp. 76-81, 2014.

[5] L. Kollipara and R. P. Zahedi, "Protein carbamylation: in vivo modification or in vitro artefact?" Proteomics, vol. 13, no. 6, pp. 941-944, 2013.

[6] Y. Zhang, M. Muller, B. Xu et al., "Unrestricted modification search reveals lysine methylation as major modification induced by tissue formalin fixation and paraffin embedding," Proteomics, vol. 15, no. 15, pp. 2568-2579, 2015.

[7] P. M. Angel and R. Orlando, "Quantitative carbamylation as a stable isotopic labeling method for comparative proteomics," Rapid Communications in Mass Spectrometry, vol. 21, no. 10, pp. 1623-1634, 2007.

[8] I. V. Shilov, S. L. Seymourt, A. A. Patel et al., "The paragon algorithm, a next generation search engine that uses sequence temperature values sequence temperature values and feature probabilities to identify peptides from tandem mass spectra," Molecular and Cellular Proteomics, vol. 6, no. 9, pp. 1638-1655, 2007.

[9] K. Ikeda, T. Monden, T. Kanoh et al., "Extraction and analysis of diagnostically useful proteins from formalin-fixed, paraffinembedded tissue sections," Journal of Histochemistry and Cytochemistry, vol. 46, no. 3, pp. 397-403, 1998.

[10] C. B. Fowler, R. E. Cunningham, T. J. O’Leary, and J. T. Mason, "Tissue surrogates' as a model for archival formalin-fixed paraffin-embedded tissues," Laboratory Investigation, vol. 87, no. 8, pp. 836-846, 2007.

[11] S. Magdeldin and T. Yamamoto, "Toward deciphering proteomes of formalin-fixed paraffin-embedded (FFPE) tissues," Proteomics, vol. 12, no. 7, pp. 1045-1058, 2012.

[12] K. Shen, J. Sun, X. Cao, D. Zhou, and J. Li, "Comparison of different buffers for protein extraction from formalin-fixed and paraffin-embedded tissue specimens," PLoS ONE, vol.10, no. 11, article 0142650, 2015.

[13] H. K. Hustoft, L. Reubsaet, T. Greibrokk, E. Lundanes, and H. Malerod, "Critical assessment of accelerating trypsination methods," Journal of Pharmaceutical and Biomedical Analysis, vol. 56, no. 5, pp. 1069-1078, 2011.

[14] S. Hildonen, T. G. Halvorsen, and L. Reubsaet, "Why less is more when generating tryptic peptides in bottom-up proteomics," Proteomics, vol. 14, no. 17-18, pp. 2031-2041, 2014. 

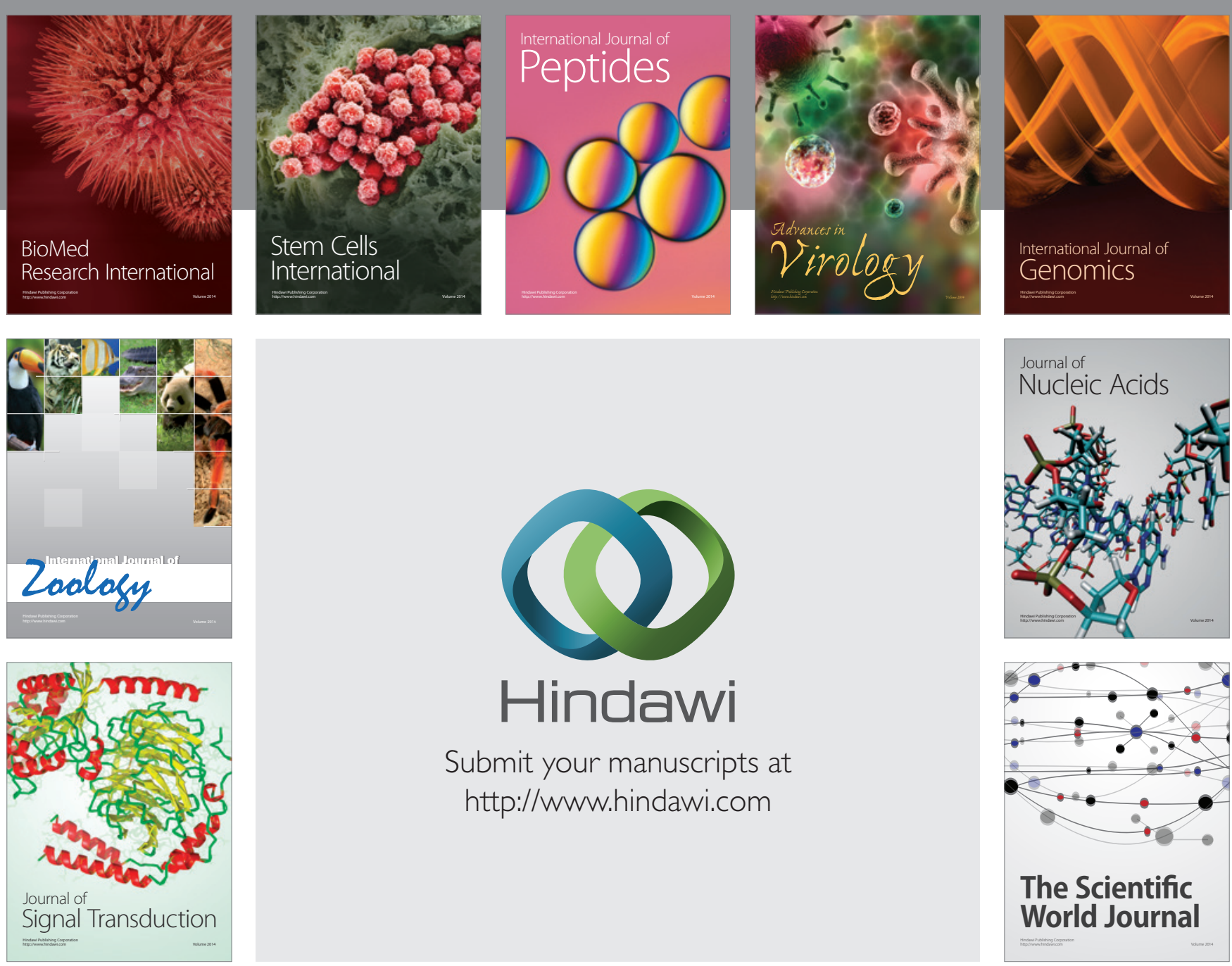

Submit your manuscripts at

http://www.hindawi.com
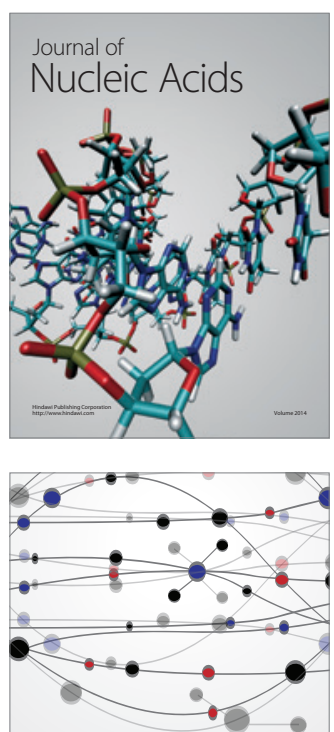

The Scientific World Journal
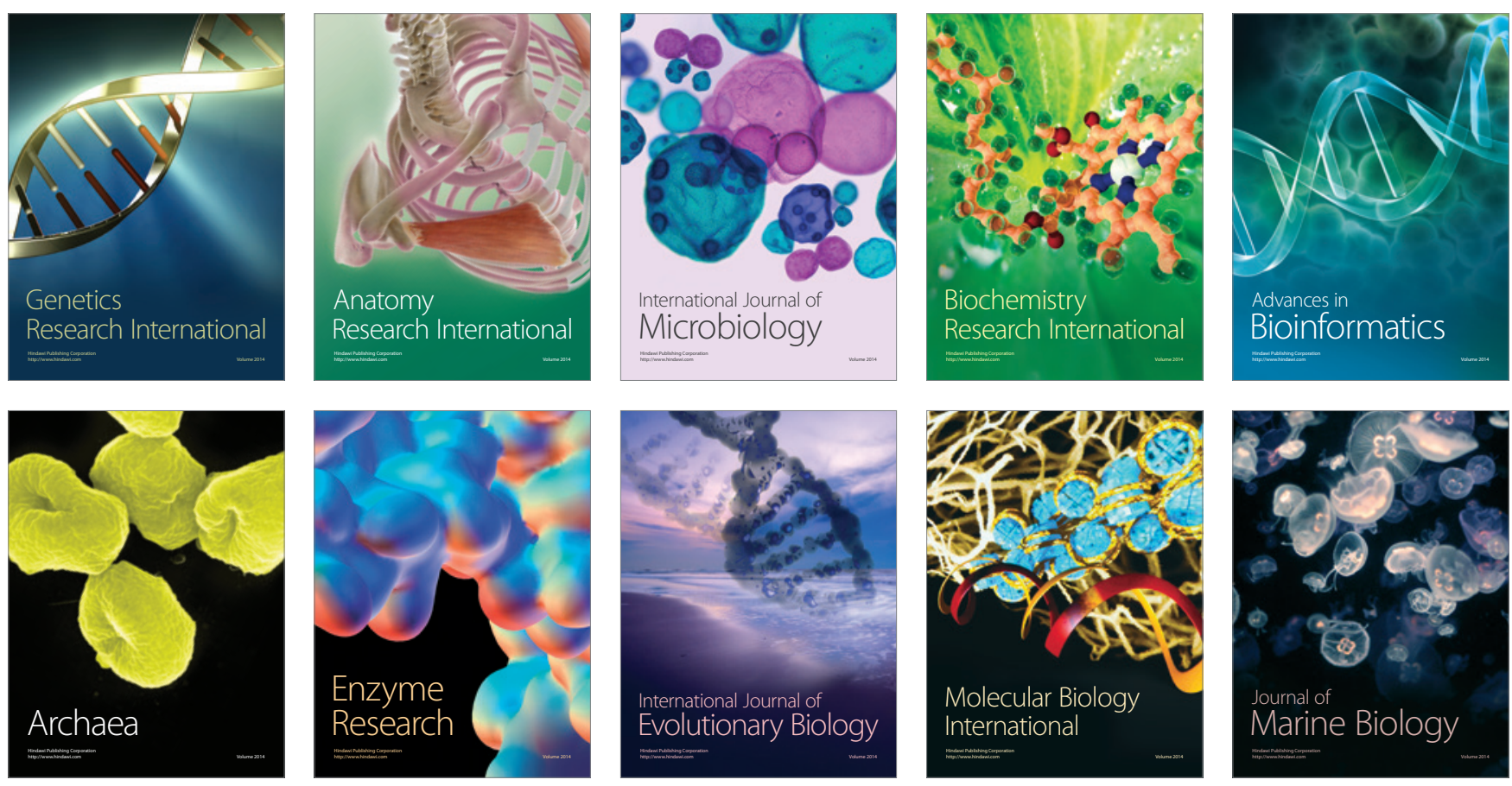